\title{
Investigation \& Control of Camel Diseases and Folk Anomalies in North \& South Punjab of Pakistan
}

\author{
Fraz Munir Khan ${ }^{1}$, Sohail Manzoor ${ }^{2 *}$, Muhammad Nawaz Malik ${ }^{3}$ and Syed Abbas Ali ${ }^{4}$ \\ ${ }^{1}$ Disease Diagnostic Laboratories Sargodha Division, Pakistan \\ ${ }^{2}$ Disease Diagnostic Laboratories Multan Division,Pakistan \\ ${ }^{3}$ Director L\&DD, Faisalabad Division, Pakistan \\ ${ }^{4}$ Provincial Diagnostic Laboratory, Pakisan
}

Submission: August 18, 2017; Published: September 27, 2017

*Corresponding author: Sohail Manzoor, Department of Disease Diagnostic, L\&DD, Pakistan, Email: manzoorsohail76@gmail.com

\section{Introduction}

In Pakistan, camels are mainly kept by the inhabitants of deserts, mountainous regions, irrigated plains, and nomadic pastoralists in subsistence production systems of the arid and semi-arid regions Iqbal, et al. [1], Jasra \& Isani [2], Khan, et al. [3], Ahmad, et al. [4], Samara, et al. [5], Pasha et al. [6]. There are about 0.328 million households linked one way or the other with camel production in Pakistan Anonymous [7]. Camel can survive and reproduce under a management system with low inputs, harsh environmental conditions and difficult landscapes in arid and semi-arid regions where survival of other animals is usually at risk Schwartz [8]. In addition to being a pack and draft animal, the camel is a good source of milk, meat and hides for the residents of the extreme desert areas. The camel milk is sold in small quantities and is also given away or shared with neighbors. The major importance of camel milk is its availability in dry seasons and during times of drought when milk from other livestock is inadequate. The dairy potential of camels appears to be higher than that of cows reared under the same climatic and management conditions Faye [9]. The milk yield ranges between 900 and 4000L in one lactation period (250-500 days). The camel meat is largely consumed by the people of rural and remote areas of Pakistan, as most of the people of cities have not developed the taste for it. The trend of milk consumption is going to be changed with time due to awareness of the people living in the cities about the medicinal importance of camel milk Khan, et al. [3], Khan, [10], Sazmand, et al. [11]. According to an estimate over 798,000 tons of milk is being produced annually in Pakistan Anonymous [7]. The trend of slaughtering camels on Eid-ulAzha (the great feast when people slaughter animals in large numbers) is increasing steadily. Being sole bread winner for the, and productivity is at stake because of parasitism, sub-clinical mastitis, and brucellosis. The worthy Secretary realized the agony of this neglected poor animal and envisioned to safeguard its health through the Project titled, "Prophylactic measures and sero-surveillance of camel and camel milk processing in Punjab". This report highlights the progress of interventions being done under the banner of the Project as a mid-term review.

\section{Survey Protocols}

In order to identify the camel's health issues, an active surveillance was conducted in selected 18 district of Punjab with a reasonable number of camel populations. These include Bahawalpur, Bahawalnagar, Rahim Yar Khan, Rajan Pur, Dera Ghazi Khan, Muzaffargarh, Layyah, Lodhran, Bhakkar, Khushab, Sargodha, Mianwali, Faisalabad, Toba Tek Singh, Jhang, Chiniot, Attock, and Jhelum. For this purpose, the fecal samples, blood samples, serum samples, milk samples and skin scraping samples/ ecto-parasites were collected from camels to gauge the prevalence of endo-parasites, blood parasites, brucellosis, sub-clinical mastitis, and ecto-parasites, respectively. The 18 Districts were further grouped into three zones as; Southern Punjab, Central Punjab and Northern Punjab [12,8].

\section{Survey Output}

For the surveillance of camel diseases under the banner of the Project, a total of 24045 (71.2\%) camels were found positive for endo-parasites, 2606 (7.7\%) for hemo-parasites, 245 (0.7\%) samples for Brucella, 1264 (3.7\%) for sub-clinical mastitis and 24499 (80.56\%) for ecto-parasites in camels.

\section{Endo-parasites}

A total of 33780 fecal samples were collected out which $24045(71.2 \%)$ were positive for endo-parasite [13]. The overall 
prevalence of endo-parasites in camels was $71.18 \%$. The detailed point to point prevalence of endo-parasites is given below:

The prevalence of nematodes was $50.33 \%$, followed in order bytrematodes $(8.54 \%)$, cestodes $(7.54 \%)$, and coccidian protozoan $(4.31 \%)$ whereas the mixed infestation of endoparasites was $0.46 \%$ in camels [14]. The results showed that in Northern Punjab the highest prevalence of nematodes was in district Khushab (59.75\%) followed in order by districts Mianwali (55.39\%), Sargodha (33\%), Jhelum (22.38\%) and Attock (20.31\%); whereas the highest prevalence of Trematodes (48.78\%) and cestodes (12.48\%) was recorded in Sargodha and Jhelum districts, respectively. The highest mixed infestation of endo-parasites was recorded only in Sargodha (16.36\%) and Jehlum (3.81\%) districts of Northern Punjab. The data indicates that the highest prevalence of nematodes was recorded in District Rajanpur (69.32\%), followed by district Bahawalnagar (53.86\%), Khan DG (50\%), Layyah (42.40\%), Muzaffarghar (41.97\%), Lodhran (38.25\%) and Bahawalpur (27.63\%). The highest prevalence of cestodes was found in district Lodhran (30.66\%) followed by district Bahawalpur (28.34\%). The highest prevalence of trematodes was also found in district Lodhran (22.19\%) followed by district Rajanpur (16.76\%) and D. G. Khan (14.66\%).The data shows the highest prevalence of nematodes in district Bhakkar (91.24\%) followed in order by districts Faisalabad (83.41\%), Chiniot (67.64\%), Jhang (37.72\%) and Toba Tek Singh (37.19\%). Both Cestodes and Trematodes were prevalent in district Toba Tek Singh at higher rates i.e. $24.79 \%$ \& $19.01 \%$, respectively; whereas the coccidian protozoan was found at higher rate $(13.91 \%)$ in district Jhang followed by district Toba Tek Singh (6.89\%). The data indicates the highest prevalence of endo-parasites (82.31\%) was in Central Punjab followed by in Southern Punjab (70.79\%) and Northern Punjab (61.54\%).

\section{Hemo-parasites}

A total of 17339 blood samples were processed in Laboratories of 18 defined districts. Out of these, 2606 (15\%) samples were found positive for hemo-parasites. The results showed the highest prevalence of Trypanosoma in camels i.e. $7.91 \%$ followed by anaplasma (3.18\%) and Babesia $(2.47 \%)$ in Punjab.The data shows the highest prevalence of Trypanosoma (20.63\%) in district Khushab followed by district Sargodha $(18.40 \%)$. The highest prevalence of Babesia was found in district Attock (14.55\%) followed by district Jehlum (8.97\%). The highest prevalence of Anaplasma (7.43\%) was reported in district Attock. The highest prevalence of Trypanosoma i.e. $13.51 \%$ was recorded in district Muzaffargarh followed by district Bahawalpur (6.31\%) and Lodhran (6.25\%). The highest prevalence for babesia was also recorded in district Muzaffargarh i.e. 3.26\%. The chart reveals the highest prevalence of Anaplasma (5\%) in district Bahawalpur of Southern Punjab. Moreover, the Theileria was only prevalent in District Lodhran $(1.04 \%)$ and Bahawalpur $(0.51 \%)$. The above chart shows that the highest Prevalence of Anaplasma (36.11\%) was recorded in district Faisalabad followed by Jhang (5.44\%) and Chiniot (4.70\%). The highest prevalence of Babesia was recorded in district Jhang (14.11\%) followed by district Toba Tek Singh (10.71\%). Moreover, the chart reveals that the Trypanosoma was also found at high rate in camel population of district Toba Tek Singh (13.57\%) followed by district Bhakkar (5.50\%) and Jhang (3.39\%). The data showed the Highest Prevalence of Trypanosoma (15\%) in North Punjab. The data shows that only $5 \%$ cases of Trypanosoma were present in Southern Punjab. The above chart shows the highest prevalence of blood parasite i.e. $20.16 \%$ in Northern Punjab followed by Central Punjab (19.69\%) and Southern Punjab (8.23\%) (Figure 1).

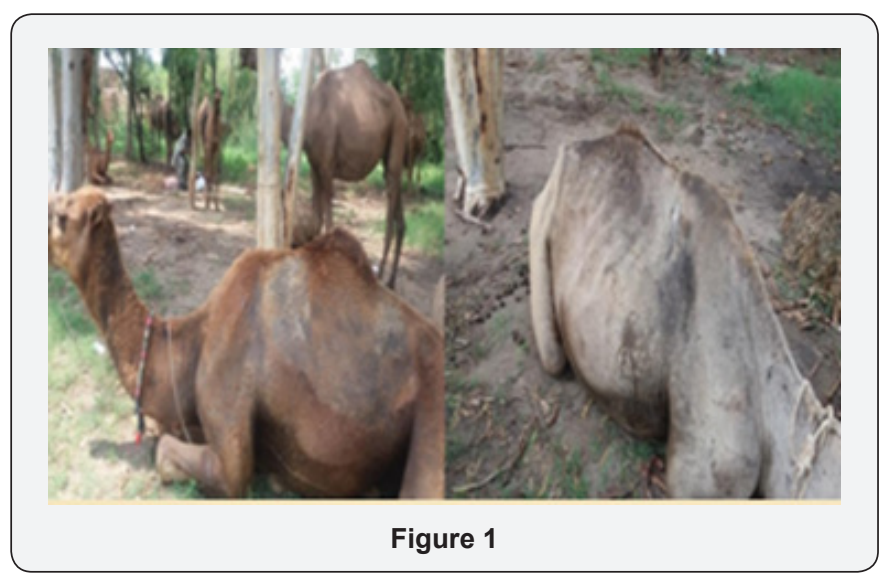

\section{Brucellosis}

A total of 16,944 serum samples of camels from 18 districts of Punjab were collected and analyzed for Brucellosis prevalence through Rose Bengal Plate Agglutination Test (RBPT) [15]. Out of the total, 245 (1.45\%) samples were found positive for Brucellosis. The data indicates the highest overall prevalence of brucellosis was in camels of South Punjab (2.05\%) followed by North Punjab (1.54\%) and Central Punjab (0.40\%).

The above chart shows the prevalence of Brucellosis in districts of Northern Punjab. The results show the highest prevalence of Brucellosis (2.31\%) in district Khushab followed by $0.86 \%$ in district Mianwali (Figure 2).

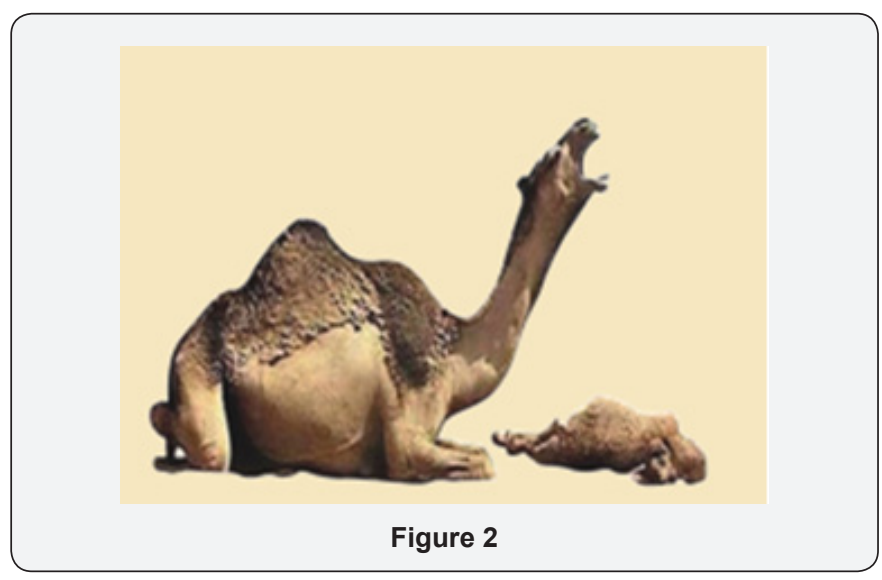




\section{Sub-clinical mastitis}

A total of 7791 milk samples were examined out of which $1264(16 \%)$ were positive for sub-clinical mastitis. The milk samples were tested in field through California Mastitis Test (Figure 3). The prevalence of Sub-clinical Mastitis in camels was $16 \%$.The above chart shows the highest prevalence of Subclinical mastitis in district Jehlum (30\%) followed by Attock (24.05\%), Sargodha (20.90\%), Khushab (18\%) and Mianwali $(15.38 \%)$.The data indicates the highest prevalence of subclinical mastitis in district Bahawalpur i.e. $29.06 \%$ followed by Lodhran (27.52\%), Rajanpur (16.75\%), Muzaffargarh (16.33\%), Bahawalnagar (13.65\%), Layyah (12.45\%), D. G. Khan (11.28\%) and Rahim Yar Khan (10.92\%).

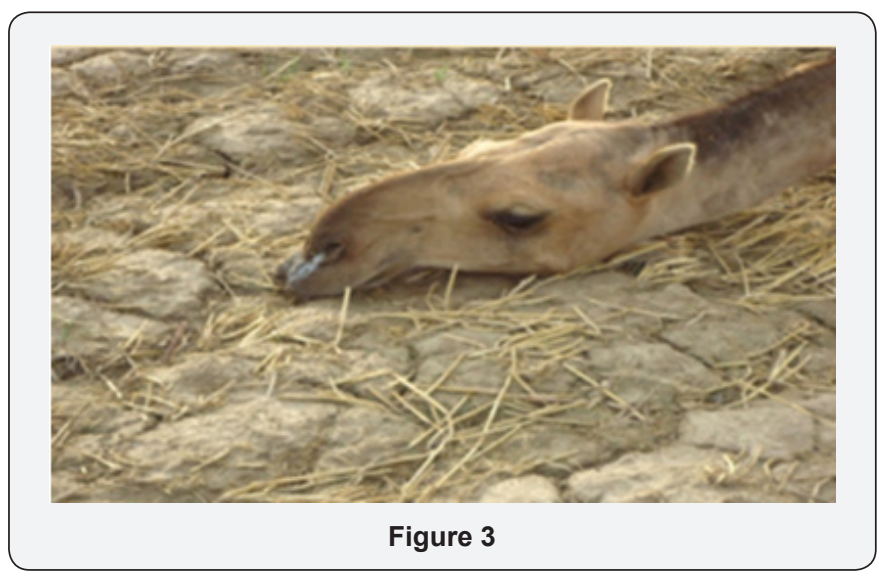

The above chart shows the highest prevalence of sub-clinical mastitis in district Jhang (27.5\%) followed by district Faisalabad (18.60\%), Bhakkar (13.65\%), Toba Tek Singh (13.04\%) and Chiniot (3.98\%).

The data indicates the highest prevalence of sub-clinical mastitis was recorded in Northern Punjab (22.80\%), followed by Central Punjab (17.24\%) and Southern Punjab (15.03\%).

\section{Ecto-parasites}

A total of 30408 camels were examined for ecto-parasites, out of which 24499 were positive. Out of these positive samples; $60.27 \%$ were positive for ticks, $1.30 \%$ for fleas, $4.15 \%$ for Lice, $8.17 \%$ for mites, $6.65 \%$ for flies and only $0.03 \%$ samples were positive for fungal infection that were reported only in district Jhelum.The data indicates the highest prevalence of ticks in Mianwali (55.95\%), followed by district Attock (55.52\%), Khushab (39.44\%) and Jehlum (35\%). The values indicate the highest prevalence of ticks infestation of camels was recorded in district Bhakkar (79.98\%), followed by Toba Tek Singh (44.35\%); whereas, the highest prevalence of mites were reported in district Jhang (18.98\%).The above chart indicates that the highest prevalence of ticks infestation was in district Rajanpur (90.03\%), followed by district D. G. Khan (88.09\%), Bahawalpur (78.59\%), Muzaffargarh (58.93\%), Lodhran (56.15\%), Layyah (39.33\%) and Bahawalnagar (32.32\%).

\section{Pneumonia in camels}

A respiratory disease (possibly multi-factorial in origin) of upper respiratory tract, characterized by fever (up to $106^{\circ} \mathrm{F}$ ) associated with dyspnea, gummy nasal discharge (occlusion of nasal passages in later stages), stretching of neck in an effort to inhale more air, and anorexia in all age groups and in either sex of camels of all breeds, occurred during May 2016. The duration of illness without intervention was up to 7 days. Camel kids mostly succumbed to the disease. The disease was wide-spread throughout the Punjab and responds readily to Oxytetracycline and Mepyramine Maleate (Figure 3). A total of 9076 cases of respiratory disease were successfully treated throughout the Punjab.

\section{Contagious ecthyma}
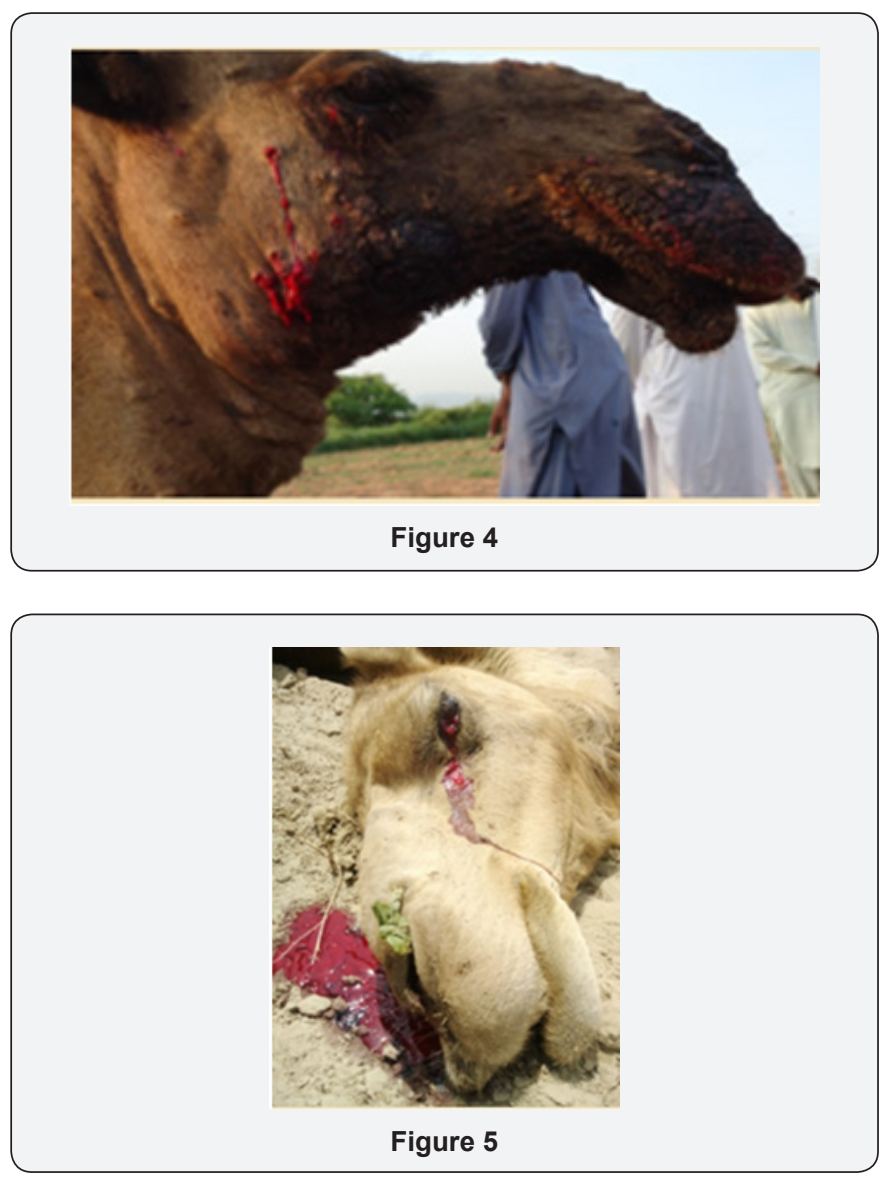

Contagious Ecthyma is an infection of the skin which can also infect man. Young camels ( 6 months to 2 years of age) are mostly affected. It may be associated with diarrhea leading to death of the animals. Animals recovering are immune for life, and nursing calves attain some degree of immunity through colostrum for the first few months of life. The high prevalence of the disease among camel populations of the Punjab demands earnest surveillance and awareness among camel herders about the disease. During the first year of the Project, a number of cases from Attock and Dera Ghazi Khan were diagnosed through ELISA and were successfully treated. Anthrax-like Disease The 
disease was encountered right at the outset of the Project in Thal districts (Bhakkar, Khushab, Mianwali, Layyah, and Jhang) and taxed the life of about 100 camels during April and May 2015. Active surveillance coupled with techniques of participatory rural appraisal was used to support the laboratory diagnosis under the banner of the Project (Figure 4 \& 5). The salient features of the disease are as under:

a. The mortality in camel population started in the last week of April 2015.

b. Most of the camels were found dead without showing any premonitory signs (i.e. sudden death). In a few cases, shivering for a few seconds leads to collapse and immediate death of the animal.

c. In most of the cases there was no oozing of blood from the natural orifices.

d. In none of the case tarry colored un-clotted blood oozed from natural orifices of cadaver.

e. In some cases oozed out blood contained bubbles (foam / froth).

f. In most of the cases, wherein blood was oozing out of natural orifices, carcass was not opened.

g. The blood failed to clot in most of the cases after death.

h. Facial and cervical swelling occurred in some of the cases.

i. Respiratory distress and diarrhea was observed in none of the cases.

j. Biting flies like Tabanid and nasal bots (Cephalopinatitillatror) were not reported by any of the informants.

k. Rigor mortis occurred in most of the cases.

l. All carcasses that were opened showed extreme congestion of colon and rectum along with hepatomegaly in Khushab. Only one carcass that was opened showed splenomegaly. Haemorrhagic enteritis of small intestine was observed in a few cases in Bhakkar.

m. Mortality occurred in both male and female camels. All the animals that encountered this occult disease were adult. No causality had occurred among suckling calves.

n. The occurrence of cases of the disease was sporadic in time and haphazard in space.

o. No disease condition with similar set of manifestations was reported from other livestock species or human beings of the locale.

It was suspected that Bacillus anthracis like organism (as for example Bacillus cereus biovaranthracis) might be involved in the causation of the disease condition.

\section{Caseous lymphadenitis}

Cases of Caseous Lymphadenitis (caused by Corynebacterium pseudotuberculosis) were found in camel populations of Layyah during searching and treating cases of sarcoptic mange. The disease was characterized by formation in the superficial lymph nodes (muscular and sub-cutaneous) and internal organs (e.g., lungs) of capsulated abscesses containing concentric layers of yellow green/white granular pus. It was realized through the active surveillance, during June 2016, that the brunt of this disease in the camel population of Layyah demands earnest efforts encompassing surveillance in all the target districts (Figure 5).

\section{Dermatitis}

Through active surveillance it was transpired during the first year of the Project that the Sarcoptic mange (caused by Sarcoptes scabiei var. cameli) is affecting camels of all ages, sexes, and breeds throughout the Punjab. It is a highly contagious disease which can spread to herdsmen or others associated with infected animals. The infection leads to a loss of appetite with a subsequent loss in condition and productivity (Figure 6). The prevalence, enormity, economic \& zoonotic importance of the disease demands its surveillance and control. In Layyah and Muzaffargarh during June 2016 under the banner of the Project active disease search and treatment of all cases was done. It was realized that the process of surveillance coupled with treatment of cases be continued during the rest of the gestation period of the Project to curb the menace of sarcoptic mange in camels of all the project-districts. To control the progression of mange, after clipping, scrubbing and washing with soap, bleaching powder solution $(0.5-1 \%)$, applied on the living skin around mange to disinfect the area followed by exposure to sun for 2 weeks and supplementation of multi-vitamin minerals mixture, was done.

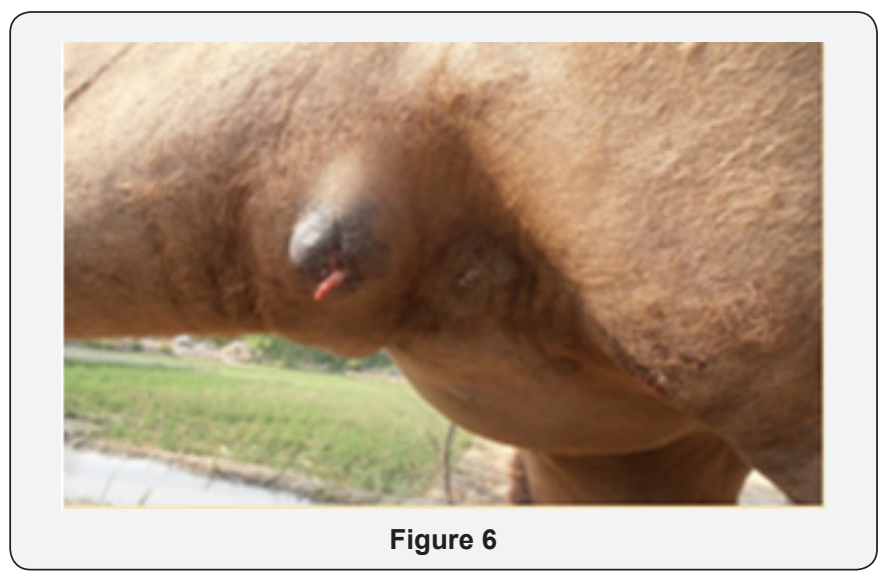

A fungus Trichophyton verrucosum cause roundish-hairlessnon-pruritic white spots with thick crusts on the head, neck and other parts of the body of camels. These lesions are called "Ringworm". Lesions may become confluent and involve extensive areas. Young animals (up to 3 years of age are mostly affected by ringworm. The active disease search during the first 
year of the Project revealed that the condition was ubiquitous in all camel-populations of the Punjab. The cases respond very well to Tincture of Iodine.

\section{Mineral deficiency}

Deficiency of various macro and micro minerals is an avenue that demands earnest efforts. Determination of normal concentration of macro-minerals, micro-minerals, enzymes and other parameters in the blood of camels of both sexes, in multiple age groups, and of different geo-graphical locations was done under the banner of this Project. This profile will help in zerodiagnosis of diseases related to abnormal serum blood chemistry level of macro and micro elements. In camels the deficiency of calcium \& Phosphorus shows stiff gait, difficult to move, increase in size of the joints especially forelimbs, lameness and sometimes arched back. Calves of camels in calcium deficiency show abnormal curvature of the shift of the long bones. The deficiency of zinc causes alopecia. The deficiency of such types results in pica (Figure 7). Pica is the licking, chewing, and eating of unusual objects like bones, grits, clothes, etc. The symptoms are mud-eating, weakness, emaciation and anemia. Pica can be cured by offering camels with mixture rich in different type of essential minerals.

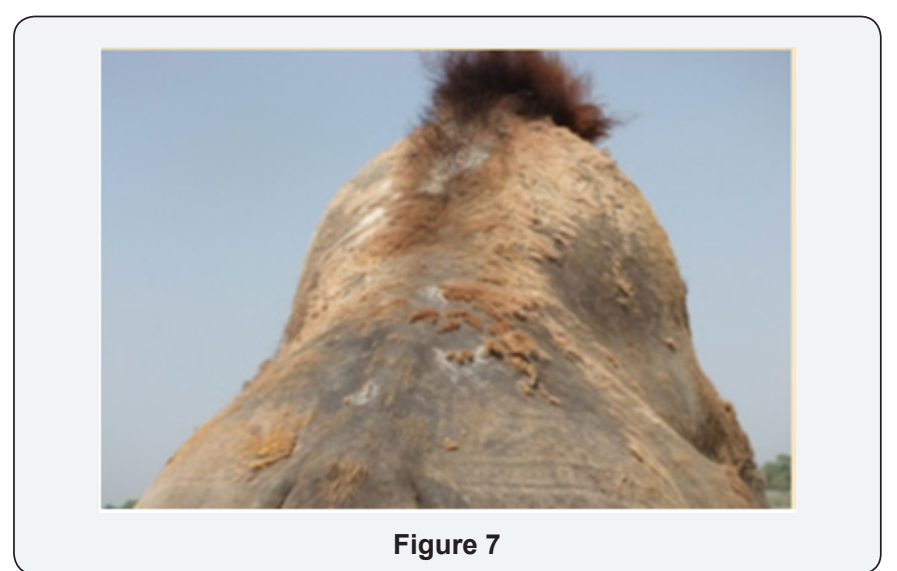

\section{Discussion}

The camels are the sole bread winners for the majority of marginalized communities the lives in the mountainous and sandy terrains of the Punjab. The well-being of this animal is directly linked with the economic uplift of these communities within their domicile. The parasites of various kinds harbor and create hindrance in the expression of their true genetic potential of these camels. No serious and comprehensive study has yet been conducted to gauge and apprise the camel herders regarding the brunt and the positive impact of these parasites on the health and productivity of these animals. The present study showed the prevalence of endo-parasites, ecto-parasites, hemoparasites in Punjab is $71.18 \%, 80 \%$, and, $15.03 \%$ respectively. The $1.45 \%$ population is positive for brucellosis. The study reveals $16 \%$ prevalence of sub-clinical mastitis in Punjab. The highest prevalence of endo-parasites was recorded in the Central
Punjab. The infestation of endo-parasites mainly reduces the health and production performance of the camels. This scenario justified the use of strategic deworming to check the impact of this menace and mass-appraisal of camel herders to adopt regular deworming as a routine management practice.

The overall point prevalence of blood parasites in camels was $15.03 \%$. The higher incidence of tick infestation predisposes camels to infestation with various hemo-parasites but may also leads to tick-paralysis. Tick-infestation invokes consistent irritation, leading to rubbing against trees or other objects; often resulting in various other invasive skin diseases and conjunctivitis. The prevalence of hemo-parasites in North Punjab was recorded to be higher (20.16\%) than Central Punjab and Southern Punjab. This high rate of prevalence in North Punjab was due to more ticks (infected with blood parasites) load and seasonal unrestricted movement of non-dewormed nomadic flocks. In Northern Punjab, ticks remain active for longer period of time due to humid environment. The study recorded the prevalence of Trypanosomes in Northern Punjab, South Punjab, and Central Punjab to be $15 \%, 5 \%$, and $4 \%$, respectively. The prevalence of babesiosis in camels was recorded as $5 \%, 1 \%$, and $3 \%$ in Central Punjab, Southern Punjab, and Northern Punjab, respectively. This is not much alarming situation in the Province. There is need to control the ticks infestation, for controlling the transmission of blood parasites and to improve the camel health and productivity. The animals infected with blood parasite become lethargic, weak, emaciated, and anorexic. Besides these, if the treatment is not done well in time, heavy infection lead to icterus, jaundice, anemia and ultimately death of the animal (Figure 8). So tick infestation should be noticed with serious concern, as they play major role in transmission of these deadly pathogens.

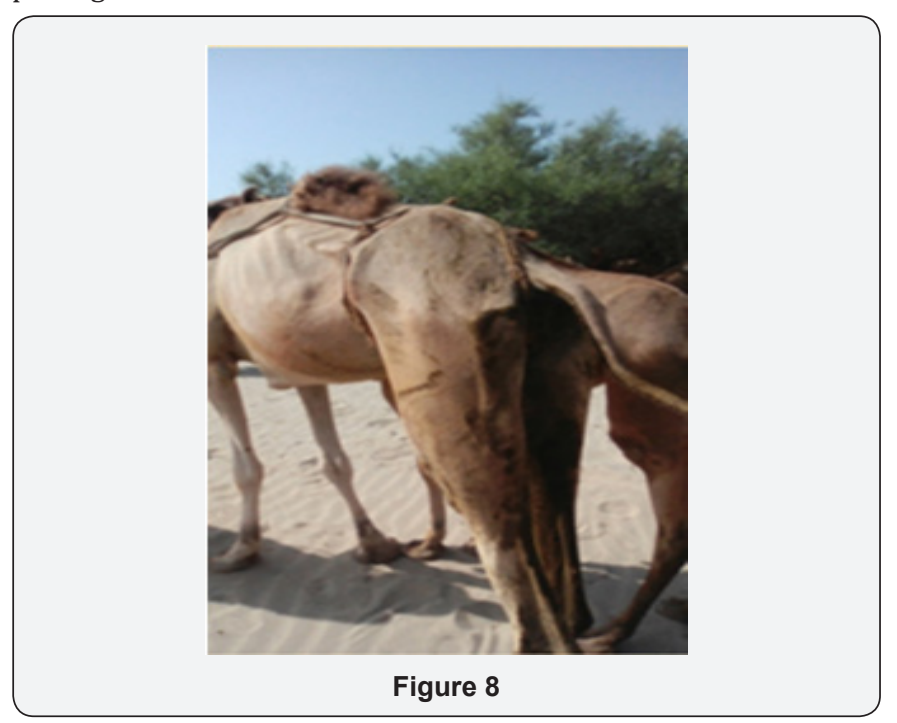

The overall prevalence of brucellosis in camels was $1.45 \%$. Because of its zoonotic importance, this state is alarming and demands earnest efforts to curb this menace. In humans, brucellosis can be a serious, debilitating and sometimes chronic disease that may affect a variety of organs. Most cases are caused 
by occupational exposure to infected animals or the ingestion of unpasteurized dairy products. The prevalence of sub-clinical mastitis in Attock and Sargodha districts of Northern Punjab was $24.05 \%$ and $20.90 \%$, respectively. The prevalence of sub-clinical mastitis was at high rate $(29.06 \%)$ in Bahawalpur. In Central Punjab District, the highest prevalence of sub-clinical mastitis was recorded in Jhang (27.50\%).

Attending various prevalent camel maladies has created awareness among camel-herders that timely veterinary attention can save their livelihood. At the same time this intervention has improved the confidence of the masses on the pro-poor policy of the Government. The farmer days and meeting have further augmented this process of confidence building and pave the way to bridge the combination gap. The women folk of camelrearing-communities in Central Punjab remained the target for changing the mindset towards strategic regular deworming and treatment against ecto-parasites and mineral deficiencies. The impact of this approach will improve the productively life of camels. Camel population was enumerated through door to door deworming campaign through ivermectin. Further refinement of the data would be made under the deworming campaign through Albendazole during the second year. This database would aid to further plan strategy for growth, and delivery of better services to camels. Annexure A gives the detail of on-going Albendazole campaign.

\section{References}

1. Jones GM, Chandler PT, Murley WR, Brown CA, Walker HW (1980) Implementation of a regional ration formulation program for the South eastern states. Journal of Dairy Science 63: 856-864.

2. Roush WB, Purswell J, Branton SL (2007) An adjustable nutrient margin of safety comparison using linear and stochastic programming in an excel spreadsheet. Journal of Applied Poultry Research 16: 514520.

3. Zgajnar J, Kavcic S (2008) Spread sheet tool for least-cost and nutrition balanced beef ration formulation. Acta Agriculture Slovenica 2: 187-94.

4. Zgajnar J, Juvancic L, Kavcic S (2009) Combination of linear and weighted goal programming with penalty function in optimisation of a daily dairy cow ration. Agricultural Economics Czech 55(10): 492-500.

5. Zgajnar J, Kavcic S, Ljubljana, Slovenia (2009) Three phase feed mix optimization for growing pigs. $17^{\text {th }}$ International Farm Management Congress, Bloomington/Normal, lllinois, USA.

6. Weaver LD, Olivas MA, Gall JC (1988) Identifying features, performance, and limitations of dairy ration formulation software a comparison of three ration formulation programs. Journal of Dairy Science 71(4): 1104-1115.

7. Zgajnar J, Kavcic S (2008) Optimization of bulls fattening ration applying mathematical deterministic programming approach. Bulgarian Journal of Agricultural Science 14(1): 76-86.

\section{Your next submission with Juniper Publishers will reach you the below assets}

- Quality Editorial service

- Swift Peer Review

- Reprints availability

- E-prints ServiceManuscript Podcast for convenient understanding

- Global attainment for your research

- Manuscript accessibility in different formats

( Pdf, E-pub, Full Text, Audio)

- Unceasing customer service

Track the below URL for one-step submission https://juniperpublishers.com/online-submission.php 